\title{
Absence of Correlation between Periodic Pulsating Auroras in Geomagnetically Conjugate Areas
}

\author{
Hirokazu Minatoya ${ }^{1}$, Natsuo SATO $^{2}$, Thorsteinn SAemundsson ${ }^{3}$, and Takeo Yoshino ${ }^{1}$ \\ ${ }^{1}$ University of Electro-Communications, 1-5-1, Chofugaoka, Chofu-shi, Tokyo 182, Japan \\ ${ }^{2}$ National Institute of Polar Research, 1-9-10, Kaga, Itabashi-ku, Tokyo 173, Japan \\ ${ }^{3}$ Science Institute, University of Iceland, Dunhaga 3, Reykjavik 107, Iceland
}

(Received November 25, 1994; Revised May 29, 1995; Accepted July 11, 1995)

\begin{abstract}
Simultaneous TV data of auroras were obtained at 3 nearly geomagnetic conjugate stations: Husafell in Iceland, and Syowa and Asuka in Antarctica, on September 9-10 in 1991. Active, pulsating auroras were found between 22:54 and 22:57 UT in both hemispheres. Pulsating spatial pattern, intensity variation, period and periodicity of periodic type pulsating auroras were used to examine possible conjugacy in the observational areas. The results reveal a distinct lack of correlation between pulsating auroras in geomagnetically conjugate stations during the event in question.
\end{abstract}

\section{Introduction}

Pulsating aurora is one of the most common type of aurora observed in the recovery phase of an auroral substorm (e.g. Oguti et al., 1978). The pulsations are characteristically quasi-periodic phenomena with a period of 0.5 to $20 \mathrm{~s}$ (Royrvik and Davis, 1977; Yamamoto and Oguti, 1982; Yamamoto, 1988).

To explain the fascinating temporal and spatial characteristics of pulsating auroras, it has been suggested that the precipitating particles are due to wave-particle interaction. Evidence for such interaction can be seen in satellite measurements (Johnstone, 1978, 1983) but the details are obscure, partly because of the difficulty in distinguishing between spatial and temporal variations in the satellite data. Ground based studies of geomagnetic conjugacy and simulation techniques can therefore play an important role.

Theoretical and simulation attempts to explain the observational results are based on the common idea that energetic and trapped particles are modulated by wave-particle interaction in the equatorial region of the magnetosphere. There are two main ideas concerning the generation mechanism of the particles that cause pulsating auroras. One is the hydromagnetic wave model (Coroniti and Kennel, 1970), and the other is the relaxation oscillation model (Davidson, 1979, 1986; Davidson and Chiu, 1986, 1991; Trakhtengerts et al., 1986; Demekov, 1991; Demekov and Trakhtengerts, 1994). Studies of geomagnetic conjugacy using instruments on board satellites and on the ground have been used to test the validity of the above ideas. Using magnetic field data from geosynchronous satellites and auroral emission data from ground based instruments, Oguti et al. (1986) showed that there is no correlation between hydromagnetic waves and pulsating auroras.

Auroral data from conjugate pairs of ground stations are useful for investigating the generation and precipitating mechanism of auroral particles. Certain studies indicating a good correlation between the north and south hemispheres as regards the shape and phase of pulsating auroras (Belon et al., 1969; Davis et al., 1971). However, cases of poor conjugacy have also been found (Stenbaek-Nielsen et al., 1973). A more detailed analysis by Fujii et al. (1987b) revealed that (1) spatial patterns of pulsating aurora are very similar in both hemispheres, and (2) pulsating patches occur in phase, but pulsating aurora of the expansion type occurs out of phase or 
asynchronously, suggesting asymmetries in the mechanism of particle precipitation.

The purpose of this paper is to give a detailed and quantitative analysis of the various characteristics such as spatial pattern, intensity variations, period and periodicity of periodic pulsating auroras.

\section{Observations and Method of Analysis}

Simultaneous auroral data by SIT-TV cameras were obtained at the nearly geomagnetic conjugate stations: Husafell in Iceland, and Syowa and Asuka in Antarctica during the time period from 22:10 UT to 01:30 UT on September 9-10 in 1991. The locations of these stations are listed in Table 1, and their relative geomagnetic locations are shown in Fig. 1. The stations are close enough to each other for their observational areas to overlap at auroral altitudes (100 $\mathrm{km}$ ), giving a wide field of view for investigation. The all-sky TV images at each station are recorded in the NTSC video signal format. The digitization and processing of the video data was carried out by the ARSAD (Automatic Retrieval System for Auroral Data; Ono, 1993; Minatoya et al., 1994).

Periodic pulsating auroras at the conjugate stations were studied for signs of spatial and temporal correlations, using the method of autocorrelation analysis (Ono et al., 1987).

Table 1. Location of conjugate-pair stations in Iceland and Antarctica. geomagnetic latitude, longitude and $L$-value are calculated with IGRF'90 model for 00 UT on January 1, 1991.

\begin{tabular}{|c||c|c||c|c||c|}
\hline \multicolumn{1}{|c||}{} & \multicolumn{2}{c||}{ Geographic } & \multicolumn{2}{c||}{ Geomagnetic } & \multirow{2}{*|}{ Station } \\
latitude & longitude & latitude & longitude & $L$-value \\
\hline Husafell & $64.47^{\circ}$ & $338.97^{\circ}$ & $65.97^{\circ}$ & $68.88^{\circ}$ & 6.03 \\
\hline Syowa & $-69.00^{\circ}$ & $39.58^{\circ}$ & $66.54^{\circ}$ & $71.79^{\circ}$ & 6.31 \\
\hline Asuka & $-71.53^{\circ}$ & $24.14^{\circ}$ & $65.41^{\circ}$ & $58.53^{\circ}$ & 5.77 \\
\hline
\end{tabular}

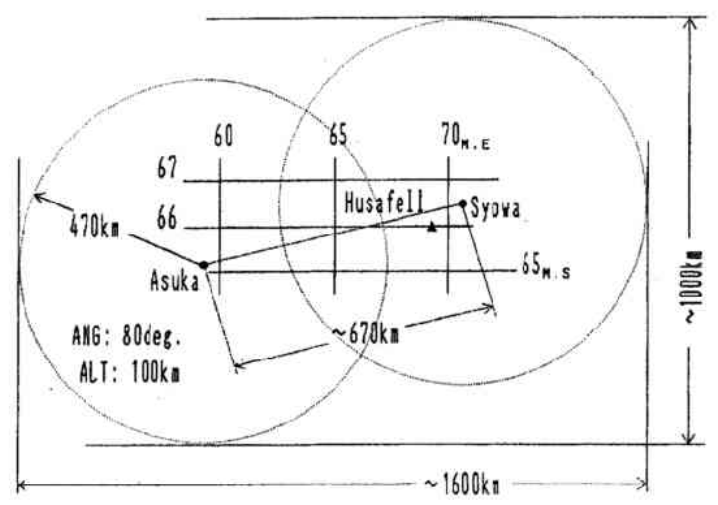

Fig. 1. Relative locations and field of view of all-sky image for 3 stations plotted against southern geomagnetic coordinates. In the case of the northern stations (Husafell), the location is the geomagnetic conjugate points of the station. The combined all-sky camera view from Syowa and Asuka extends about $1600 \mathrm{~km}$ in longitude and $1000 \mathrm{~km}$ in latitude, assuming that the height of aurora is $100 \mathrm{~km}$ and the maximum effective angle of observation is 80 degrees. 


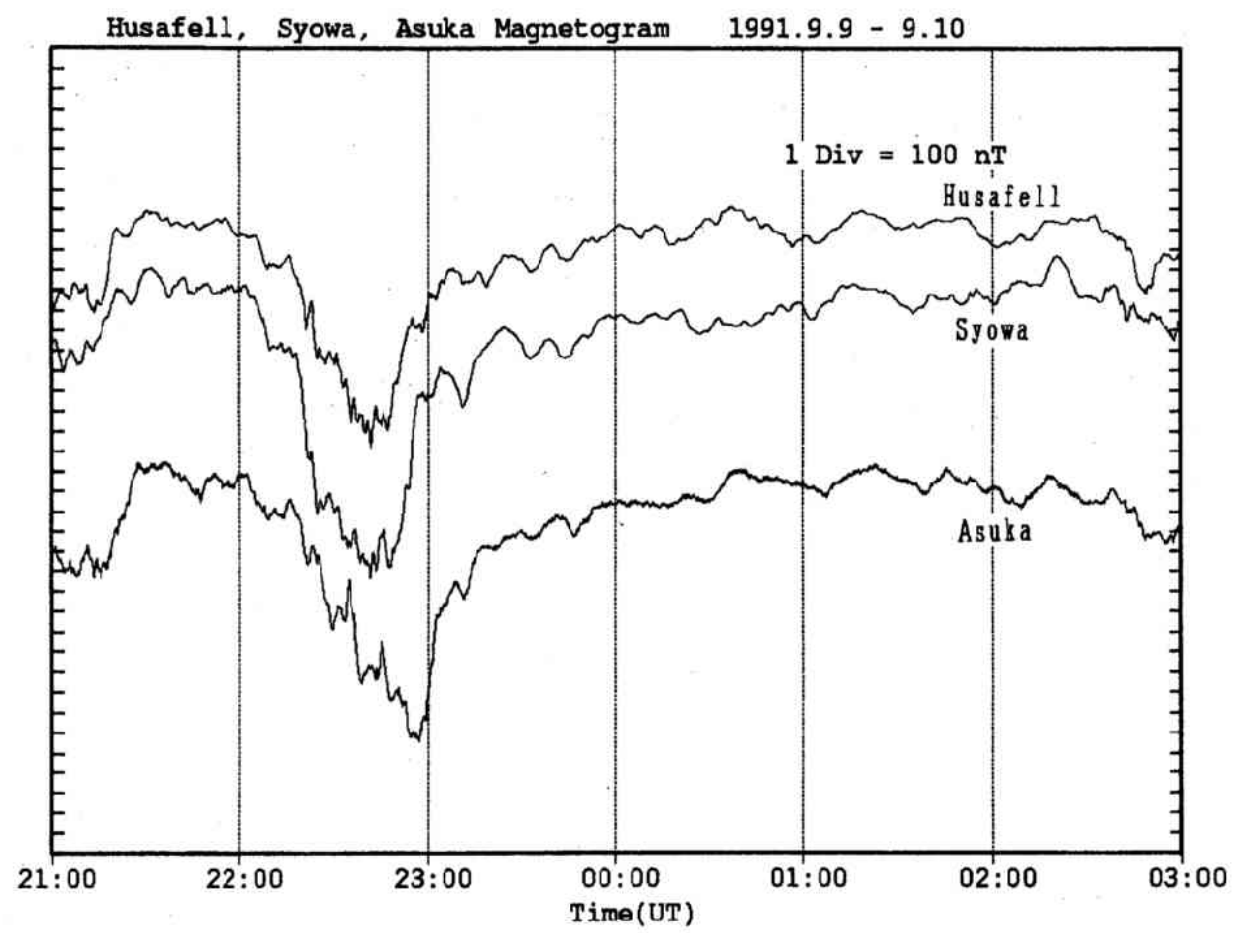

Fig. 2. Temporal variations of the $H$-component of the magnetic field observed at 3 stations in the interval of 21:00 UT-03:00 UT, September 9-10.

\section{Results}

Active auroras were observed in a clear sky at all locations. Fig. 2 shows temporal variations of the geomagnetic field ( $H$ component) at the three stations. As shown in Fig. 2, strong geomagnetic disturbances, with an amplitude of 1200-1800 nT in $H$, occurred from approx. 22:10 UT to 23:00 UT. This was followed by a recovery phase from about 23:00 UT until 03:00 UT. The $K p$ index was $7_{0}(21-24 \mathrm{UT})$ to $5_{0}$ (00-03 UT).

Many active, pulsating auroras were seen inside large scale torch structures (Akasofu, 1974) from 22:20 UT to 23:00 UT in both hemispheres. For analysis we selected stable, periodic pulsating auroras observed from 22:54:00 to 22:57:00 UT. The study was restricted to this interval, because at other times the drift speed of pulsating auroras was generally too high to permit analysis with our method. In addition, the Husafell data from 22:20 UT to 22:40 UT were unsatisfactory because of saturation effects.

Figures 3 and 4 show simultaneous all-sky images and coordinate-transferred images for the three stations at 22:55 UT. The images are oriented so that the vertical axis indicates geomagnetic latitude, while the horizontal axis indicates geomagnetic longitude. The auroral images have been projected onto rectangular geomagnetic coordinates deduced from the IGRF 1990 model, on the assumption that the aurora is at a height of $100 \mathrm{~km}$. The range in longitude is $64-76$ degrees for Husafell and Syowa, and 52-64 degrees for Asuka. The latitudinal range is 64-68 degrees for all images.

The southern hemisphere images from Syowa and Asuka in Fig. 4 show a large torch structure, ranging from the western edge of Asuka's field of view, to near the zenith of Syowa. The northern hemisphere picture from Husafell shows a structure as large as southern one, in the western half 
Date: 1991.09 .09 Time: $22: 55: 00$ UT

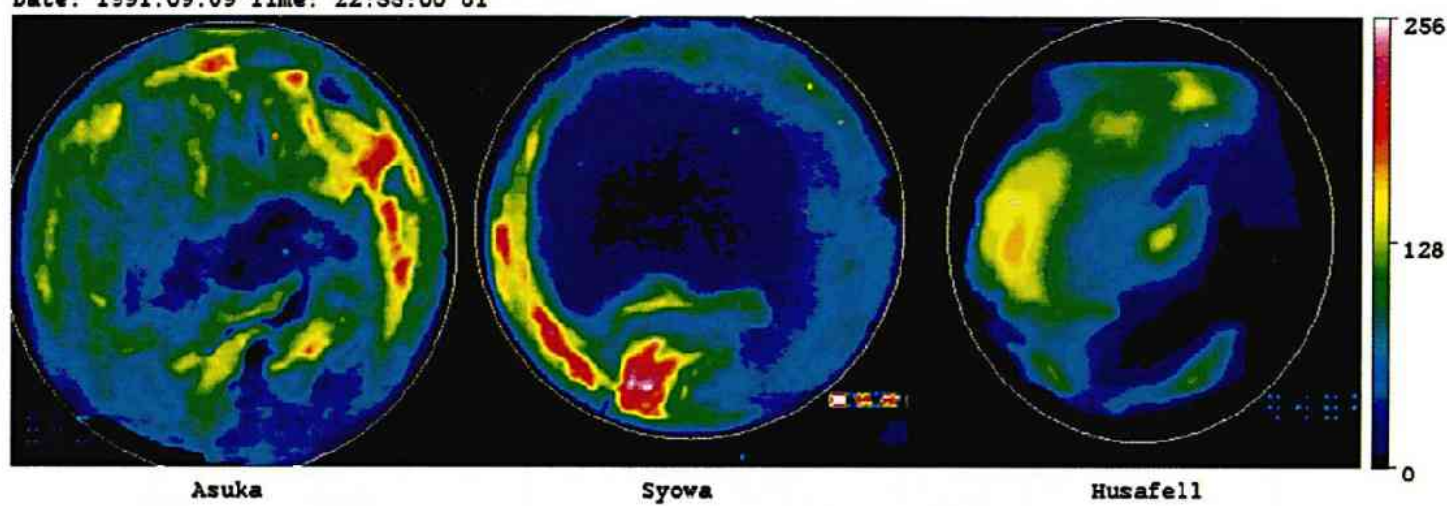

Fig. 3. Auroras in all-sky image at 22:55 UT. Intensity is indicated by a color bar. In these pictures, up indicates higher geomagnetic latitude and east is towards the right.

Date: 1991.9 .9

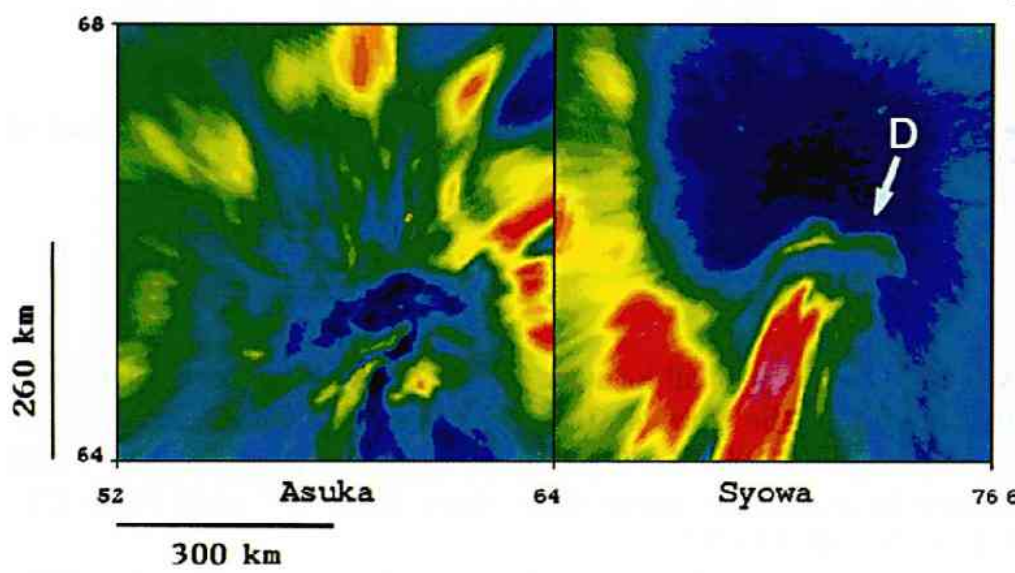

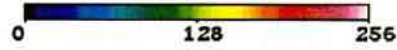

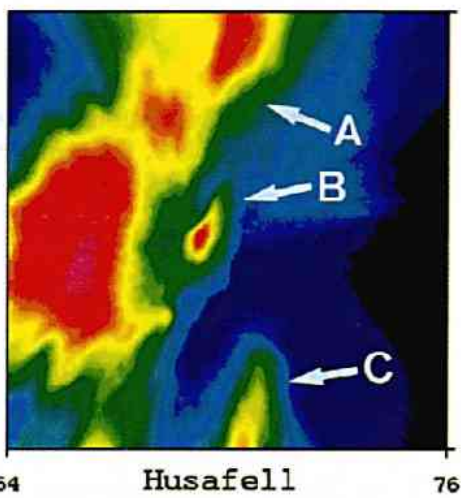

Fig. 4. Auroras in coordinate-transferred image at 22:55 UT. Intensity is indicated by a color bar. Horizontal and vertical axes indicate geomagnetic longitude and latitude, respectively. The longitudinal range is 64-76 degrees for Husafell and Syowa, and 52-64 degrees for Asuka. The latitudinal range is 6468 degrees for all stations. Pulsating auroras were seen in wavy structures indicated by A, B, C and D.

of the image. According to the video data, the pulsating auroras seen all over the sky at Asuka were of the patchy type (Yamamoto, 1988). At Husafell and Syowa, on the other hand, pulsating auroras of the expansion type (Yamamoto, 1988) were observed at B, C and D, while the patchy type was seen at $\mathrm{A}$, on the eastern edge of the torch structures.

The location of torch structures and types of pulsating auroras, as mentioned above, suggest that Husafell and Asuka are not in a conjugate relation to each other, while Husafell might be conjugate with Syowa.

A more detailed investigation was carried out to compare the data from Husafell and Syowa, using autocorrelation analysis to represent the pulsating spatial pattern, intensity variations, 


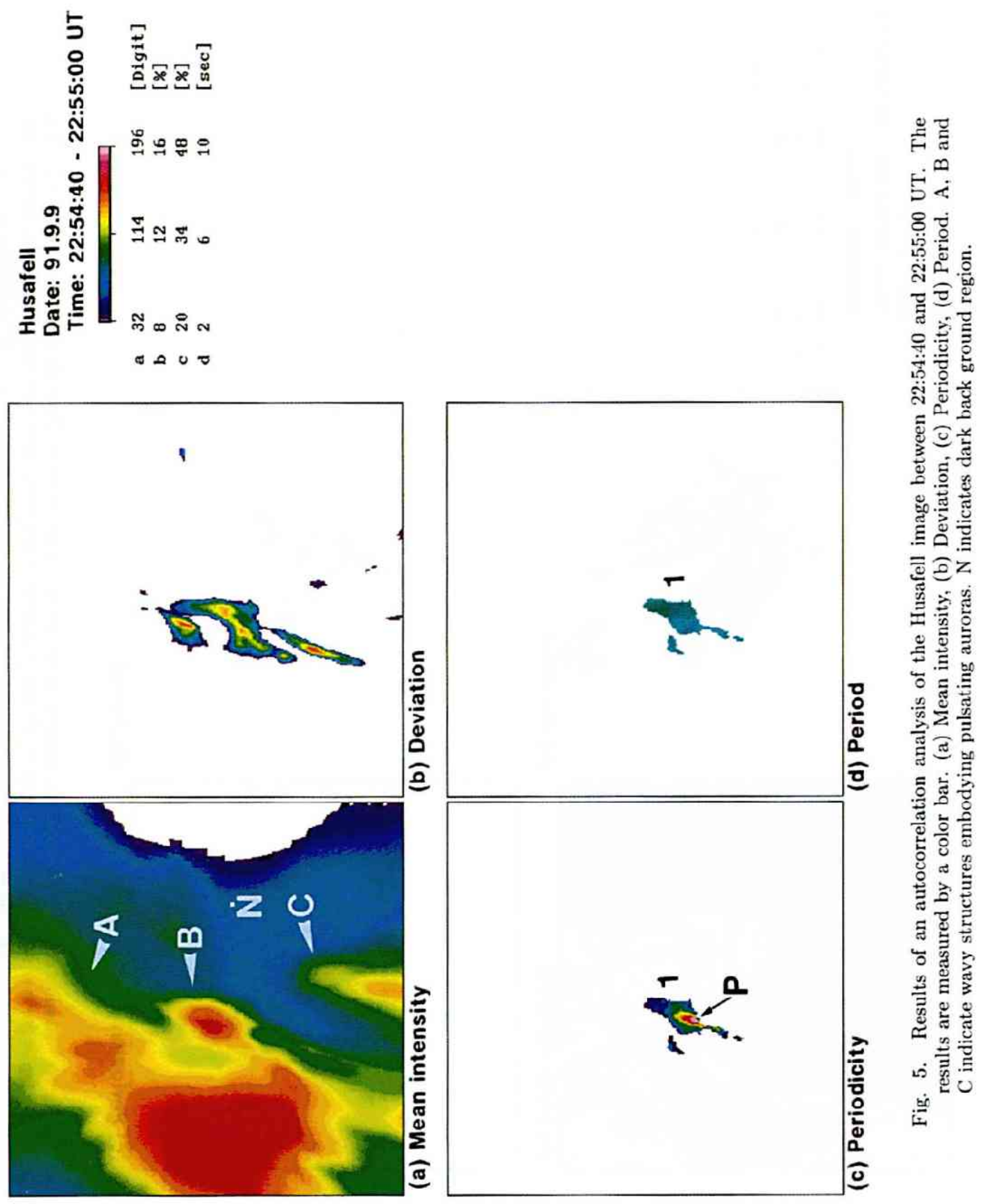




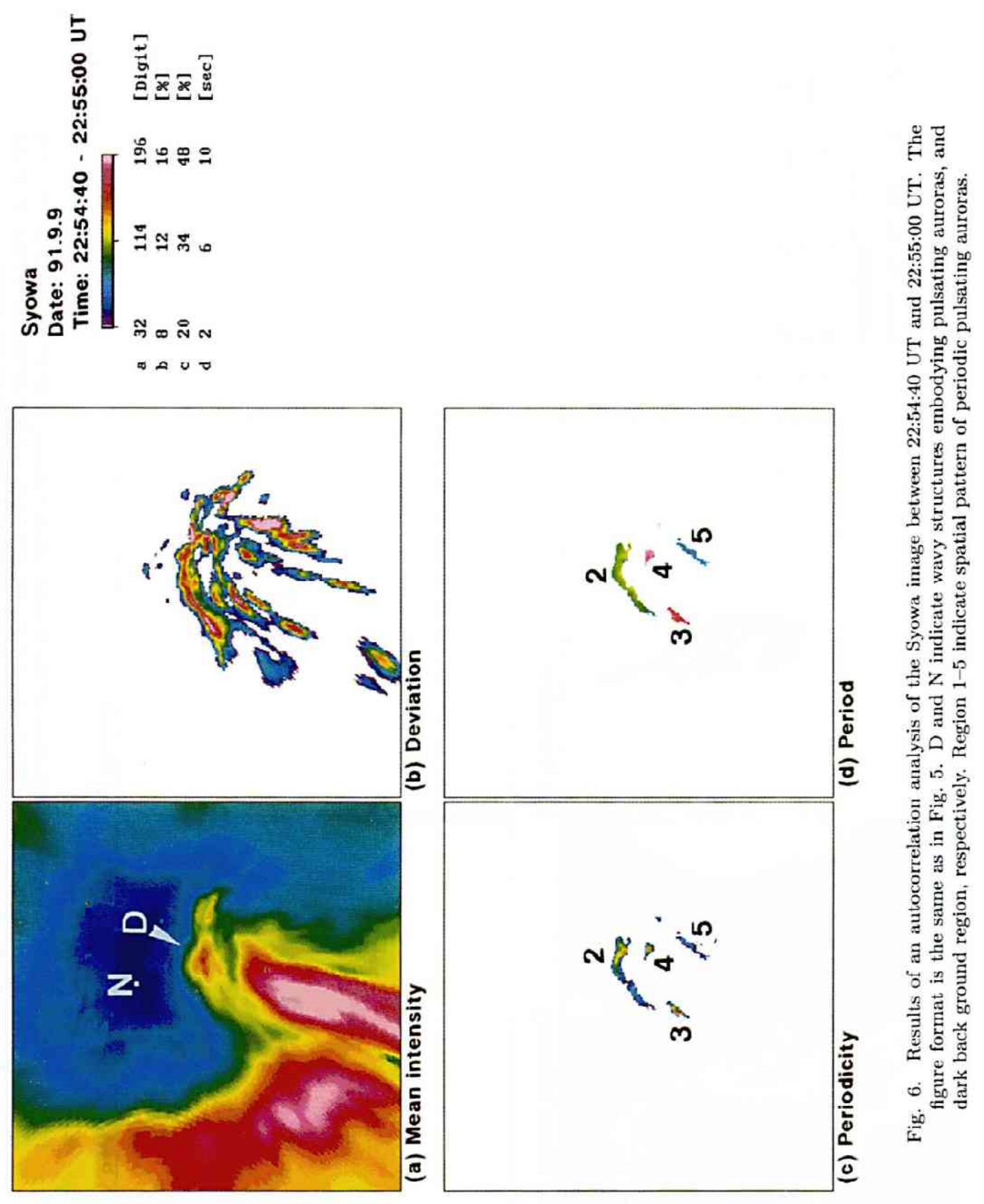


periodicity and period, both spatially and temporally. The TV image data were digitized at a sampling rate of $0.2 \mathrm{~s}$ in order to analyze pulsating auroras with a period of 4-10 $\mathrm{s}$.

\subsection{Example 1, 22:54:40-22:55:00 UT}

Autocorrelation analysis was applied to the intensity of each image pixel from the Husafell and Syowa data for the time interval 22:54:40-22:55:00 UT. The results are shown in Fig. 5a-d and Fig. $6 \mathrm{a}-\mathrm{d}$, respectively. The panels (a-d) in Figs. 5 and 6 represent (a) mean intensity, which is time-averaged intensity on each image pixel over the analysis interval, (b) deviation, which is the relative standard deviation of intensity variation measured from the mean intensity, (c) periodicity and (d) period, i.e. the maximum coefficient and the time lag for the autocorrelation function, respectively.

In Fig. 5a, three wavy structures, $\mathrm{A}, \mathrm{B}$ and $\mathrm{C}$ are found near a vertical line bisecting the field of view along longitude $\approx 70 \mathrm{deg}$. In Fig. $6 \mathrm{a}$, a similar structure, $\mathrm{D}$, is also found at the center of image (longitude $\approx 70 \mathrm{deg}$. and latitude $\approx 66 \mathrm{deg}$.). Pulsations were seen in each of these structures. If the field of view from Husafell covers the conjugate area of Syowa, similar characteristics of pulsating auroras might be expected at both stations.

Figures $5 \mathrm{~b}$ and $6 \mathrm{~b}$ show regions where a deviation exceeds $8 \%$. A large spatial pattern with the deviation of $8-24 \%$ can be seen roughly along the structure B. Small deviations of less than $6 \%$ were found in pulsating auroras at $\mathrm{A}$ and $\mathrm{C}$, not correlated with those at the structure D. A deviation similar to that found in structure B is found at D, but the spatial pattern is different. The large difference in shape would suggest that the structures $\mathrm{B}$ and $\mathrm{D}$ are not conjugate to each other.

Figures $5 c$ and $6 \mathrm{c}$ show strongly periodic regions with a periodicity of more than $20 \%$. The strongly periodic region $\mathrm{b}$ is recognized along the structure B in Fig. 5c and Fig. 5b. Figure 5d shows that region 1 has a period of $4-5 \mathrm{~s}$. Figure 7 a shows the intensity variation at $\mathrm{P}$, the point of maximum periodicity within region 1, as a typical large and regular pulsation. The intensity level of the point $\mathrm{N}$ in Fig. 5a is also shown in Fig. 7a as an example of the dark background level. The period and periodicity at point $\mathrm{P}$ are $4.0 \mathrm{~s}$ and $50 \%$ respectively.

Figures $6 c$ and $6 \mathrm{~d}$ shows periodic pulsating regions with a periodicity of more than $20 \%$ denoted by $2-5$ in structure $\mathrm{D}$, with a period of $4-9 \mathrm{~s}$. Figures $7 \mathrm{~b}-\mathrm{e}$ shows intensity variations of the most periodic point in each region (2-5) and the dark background level of the point $\mathrm{N}$ in Fig. 6a. They differ from that in structure B as regards size and spatial pattern of pulsation. Region 2-4 shows dissimilar periods (about 5-9 s) and periodicities (about 20-40\%). Region 5 alone shows a similar period (about $4 \mathrm{~s}$ ) and periodicity (about 26\%) as region 1 . We therefore conclude that there is no correlation between the structures $\mathrm{B}$ and D.

\subsection{Example 2, 22:55:30-22:55:50 UT}

This time interval was subjected to the same method of analysis as that in Example 1. The results are shown in Figs. 8a-d and 9a-d. The figure format is the same as in Fig. 5. The wavy structures A, B and C are seen in Fig. 8a, and the structure D is seen in Fig. 9a. Pulsations are observed inside the structures. Regular pulsations of large amplitude are seen in the structure B and D, as was the case in Example 1.

Figures $8 \mathrm{~b}-\mathrm{d}$ shows a rather large size pulsating region, along the structure $\mathrm{B}$ at Husafell. Region 1 has a large amplitude (8-24\%) and a high periodicity $(20-48 \%)$ with a period of $4-5 \mathrm{~s}$. Figures $9 b-d$ shows regions of large amplitude (8-24\%) and rather high periodicity (20-36\%) observed at Syowa. These regions have a period of $6-9 \mathrm{~s}$. It is notable that the pulsating regions $2-5$ in the structure D are very small. Therefore, the pulsating auroras in structure B and D are similar in amplitude but dissimilar in spatial pattern, size and period. This suggests that there is no correlation between the two structures. 

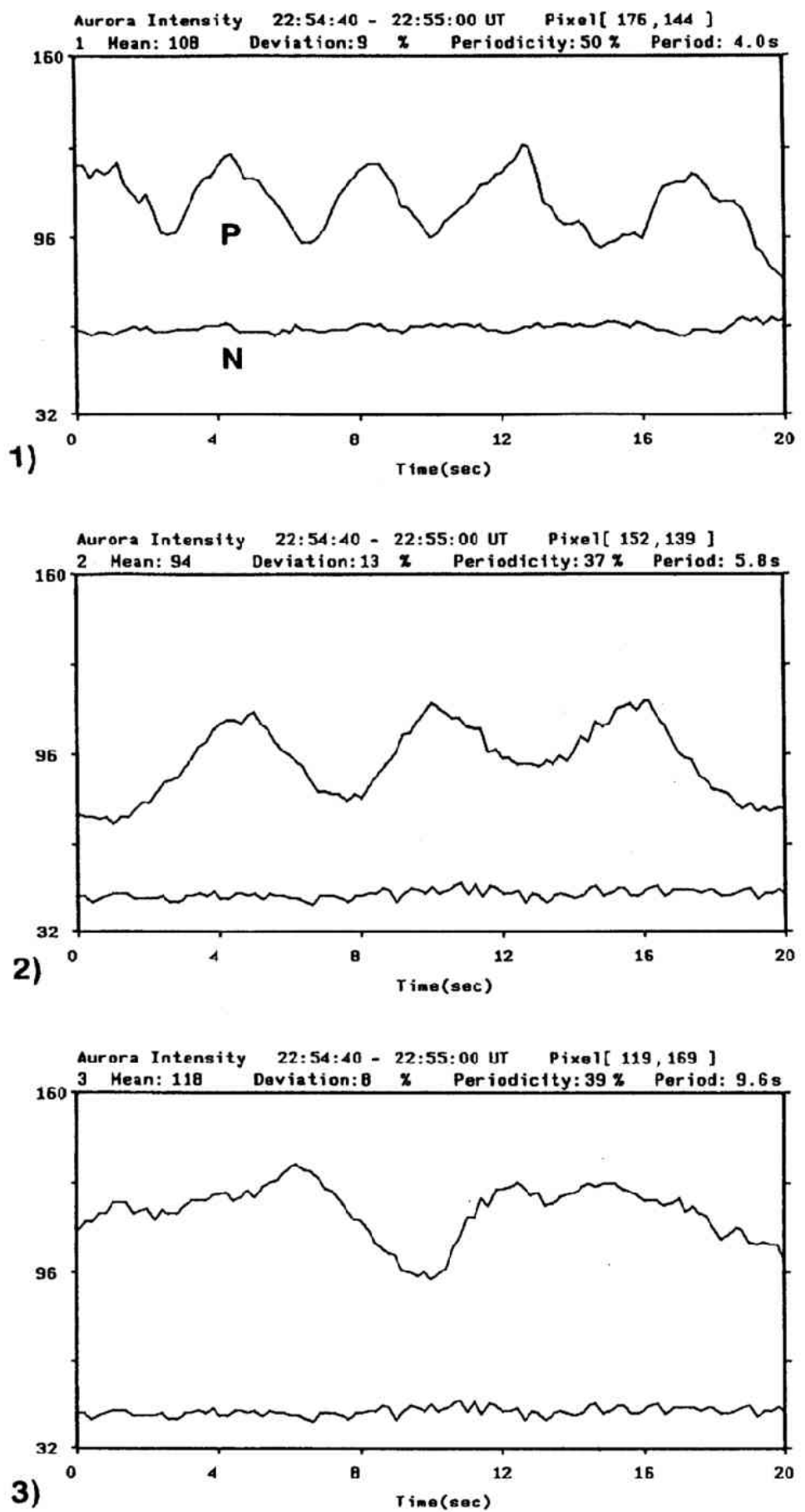

Fig. 7. Figures 1-5 shows examples of intensity variation within regions, 1-5 in Fig. 5 and Fig. 6 in the interval of 22:54:40-22:55:00 UT. Intensity variations are represented on a relative scale. $\mathrm{P}$, the point of maximum periodicity within region 1 , and $\mathrm{N}$, the point as an example of the dark back ground level. 

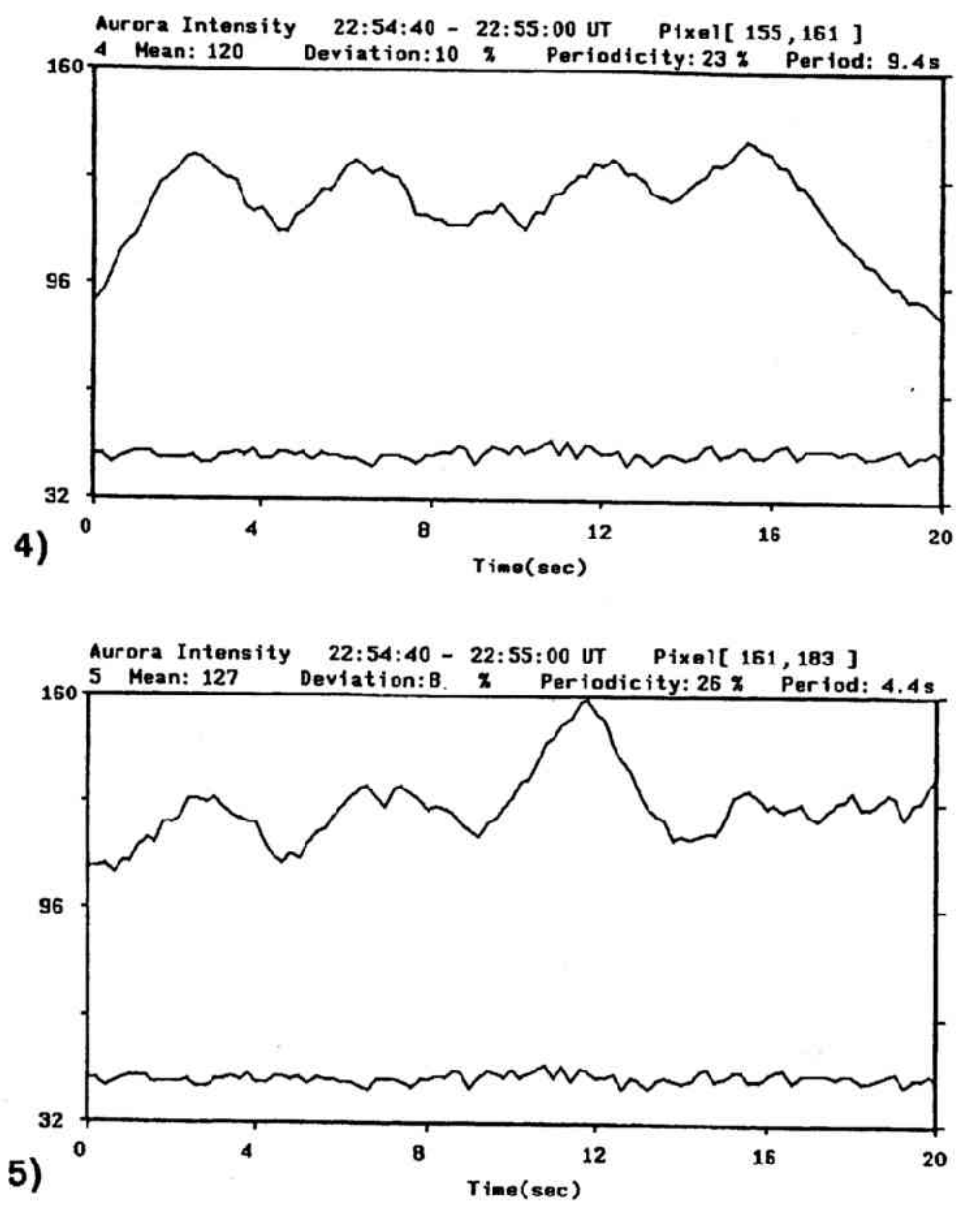

Fig. 7. (continued).

The above results given by Example 1 and 2 indicate that there were no similar pulsating auroras showing conjugate relationship within the wide field of view of Husafell, Syowa and Asuka at the time of observation.

\section{Discussion}

In order to interpret our results, we must consider two possibilities. One is a lack of conjugacy caused by a large asymmetry in the geomagnetic field line structure in the two hemispheres. The other possibility is that the generation and precipitation mechanism of auroral particles is asymmetric in the two hemispheres. These two cases will now be discussed.

\subsection{Asymmetry in geomagnetic field line structure}

Longitudinal displacements of $100-200 \mathrm{~km}$ for pulsating aurora have been reported by Stenbaek-Nielsen et al. (1972). This circumstance was interpreted as deformation of the geomagnetic field structure. Our results might also be explained in the same way, but the displacement required is much larger. If pulsating auroras in the structure B of Fig. 4, which is located near the zenith of Husafell, have a conjugate in the opposite hemisphere, one would expect to find this 

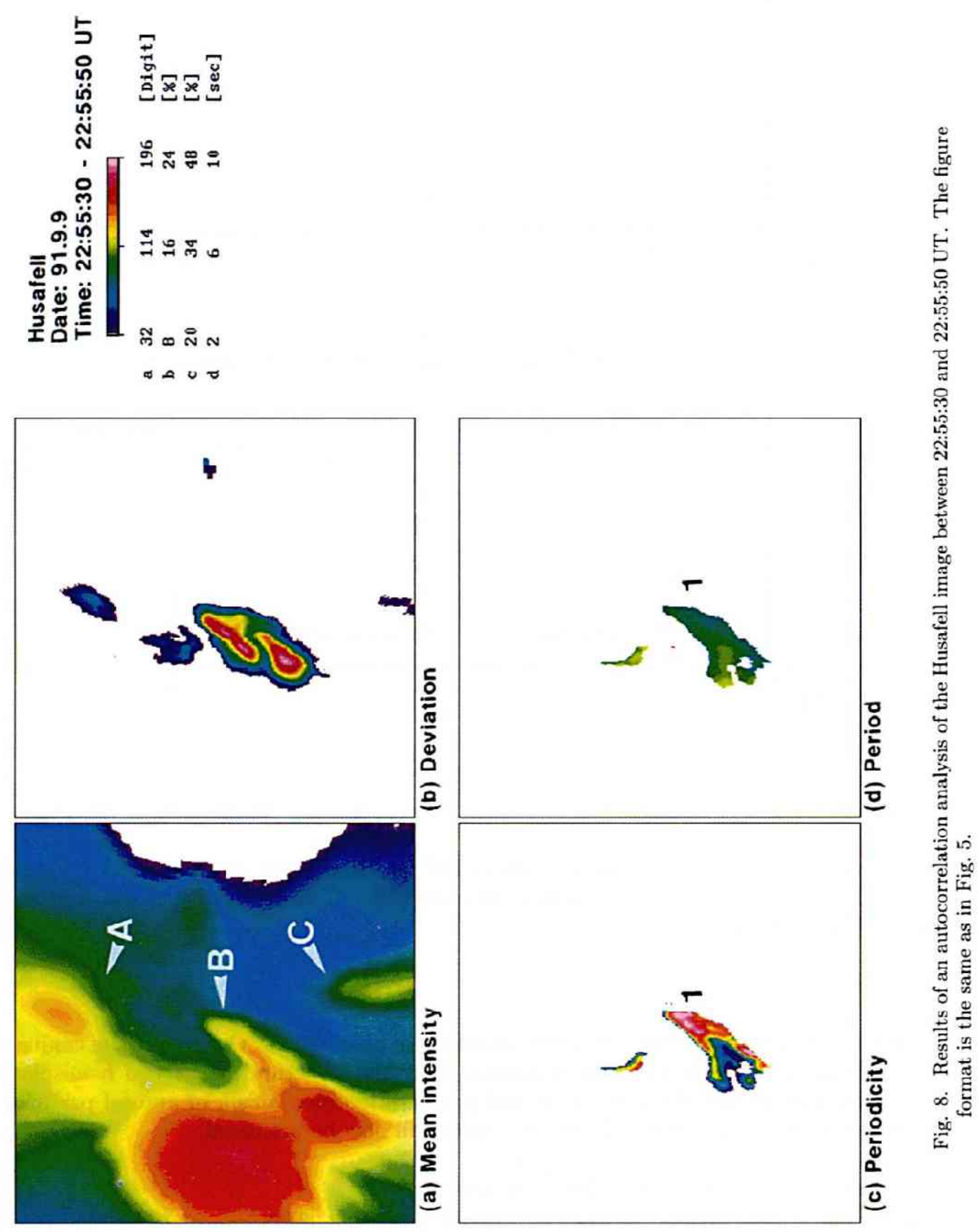

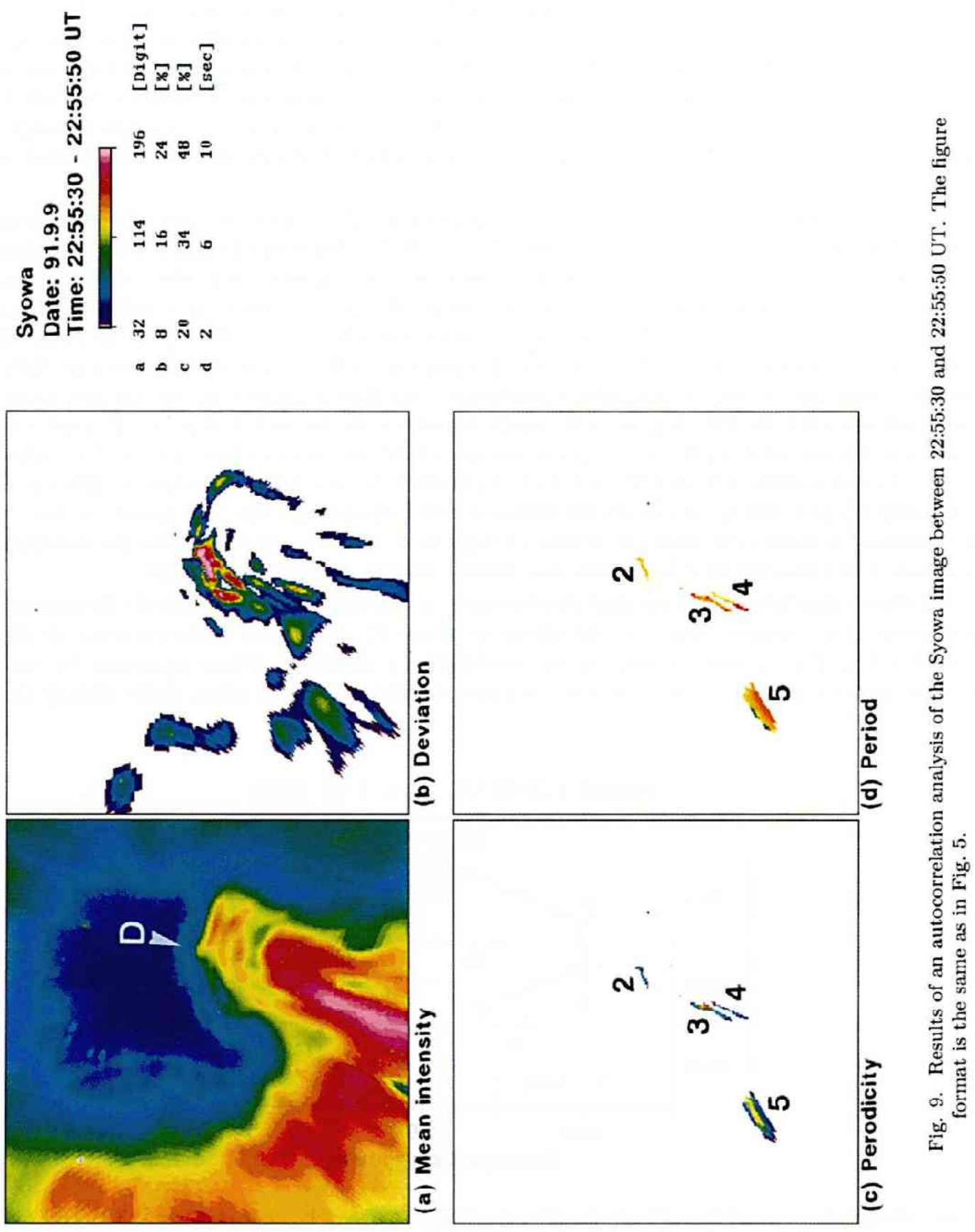
near D of Fig. 4 because it is located along the eastern edge of the torch structures. There is, in fact, good reason to believe that the two points, B and D were joined by a geomagnetic field line at the time of observation. A study by Minatoya et al. (1994) found a good correlation between three pairs of auroral torch structures seen at Husafell and at Syowa during the period 22:20 to 23:00 UT on September 9, while the correlation between Husafell and Asuka remained poor. The present results relate to pulsating auroras around one of these three torch structures. To explain why the pulsating auroras did not exhibit conjugacy, one could postulate that the conjugate point of Husafell shifted away from Syowa at during the brief interval 22:54:00 to 22:57:00 UT. However, this shift would have to be larger than $\pm 260 \mathrm{~km}$ in latitude or $\pm 300 \mathrm{~km}$ in longitude to place the conjugate point outside the area covered by the Syowa all-sky camera. Such a large shift seems very unlikely, as we shall see.

Latitudinal displacements of 50-100 km for pulsating aurora have been reported by previous workers (Stenbaek-Nielsen et al., 1972; Fujii et al., 1987b). Such displacements may be caused by large scale currents flowing in the magnetosphere and by a geometrical effect of the tilt angle of the geomagnetic dipole axis from the ecliptic plane. Figure 10 shows the conjugate points of Husafell mapped onto southern IGRF geomagnetic coordinates, as calculated by the IGRF 1990 model and Tsyganenko's 1987 (T87) model (Tsyganenko, 1987). The T87 model can indicate temporal variations of the geomagnetic coordinates for different values of the $K p$ index caused by magnetotail current, the ring current, magnetopause current and change of tilt angle of the dipole axis. Figure 10 is a plot of the point calculated by the model when $K p$ has the values $3_{0}$ and $\geq 5-$ between 22:00 UT and 02:00 UT on September 9-10 in 1991. Latitudinal differences of 0.2-0.7 degrees (30-90 km) are observed between IGRF model and the T87 model for $K p \geq 5-$. This tendency is consistent with the results of Fujii et al. (1987a). However, the displacement of more than $\pm 260 \mathrm{~km}$ required to explain our present results, is very much larger.

Another candidate for latitudinal displacement is auroral electrojet currents flowing in the ionospheres. For example, negative disturbances of the $H$ component observed from 22:10 UT to 23:00 UT in Fig. 2 were caused by the westward jet currents. These appeared to contain the differences of $20-30 \%$. For example, negative disturbance from quiet level (during 21:20-

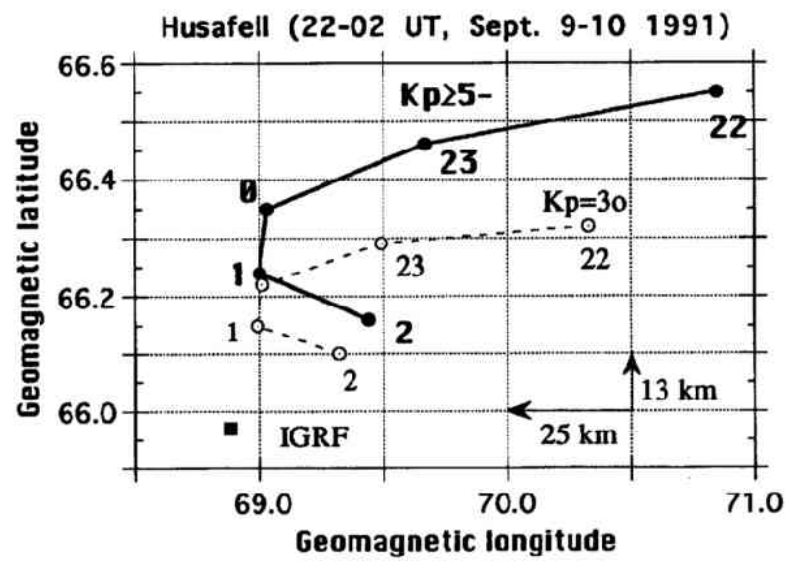

Fig. 10. Conjugate points of Husafell calculated by the IGRF 1990 model and Tsyganenko's 1987 (T87) model mapped onto southern geomagnetic coordinates at the height of $100 \mathrm{~km}$. The temporal variation of the position in the T87 model for different values of the $K p$ index is also shown in the figure for the interval 21:00 UT to 03:00 UT on September 9-10 in 1991. Dots and a solid line, circles and a dash line means conjugate points at $K p \geq 5$ - and $K p=3 o$ in T87 model, respectively. A square indicates a conjugate point in IGRF model. 
22:00 UT) reached about $1100 \mathrm{nT}$ at Husafell and $1400 \mathrm{nT}$ at Syowa, respectively. Although the asymmetry in the jet current intensities in both hemispheres may effect on the displacement, we think it is negligible from the following reasons. When the jet currents with the same intensity flows in both hemispheres, conjugate auroras at both hemispheres are not displaced because the field lines deformed symmetrically in latitude. Even if the differences are due to the asymmetry of the jet current intensity, it would produce very small displacement. Because the effect of the jet current, which is very small near the earth comparing with the geomagnetic field, is still estimated to be very small at a long distance since it decrease in proportion to $r^{-2}(r$ : distance from the jet current).

Large scale field-aligned currents are another possible cause of displacements of auroral forms (Iijima and Potemra, 1976, 1978). Such currents are not incorporated into T87 model. Nishitani (1992) and Donovan (1993) find a large and symmetrical deformation of geomagnetic field line structure for longitude in the T87 model when the field-aligned currents have the same intensity in both hemispheres. In their model, a longitudinal displacement of about 10-11 degrees in geomagnetic longitude is indicated when there are strong field-aligned currents in both hemispheres. A difference of $20-30 \%$ in the intensity of field-aligned currents in the two hemispheres could produce a longitudinal displacement of 90-150 km, which is within our observational area. It would seem, therefore, that neither electrojet currents nor field-aligned currents can cause sufficiently large longitudinal or latitudinal displacements to explain our observations.

\subsection{Asymmetry in the generation and precipitation mechanism of auroral particles}

Fujii et al. (1987b) reported asymmetries in intensity variations for pulsating auroras of the expansion type. They showed that expansion type aurora in one hemisphere occurred out of phase or asynchronously with such aurora in the other hemisphere. However, they found a similarity in spatial patterns of pulsating auroral patches in both hemispheres, which is different from our results.

It seems possible that the dissimilarities in intensity variations and pulsating spatial patterns in our results could be caused by asymmetries in the generation and precipitation mechanism of the particles causing pulsating auroras in opposite hemispheres.

A possible generation mechanism for auroral pulsation particles has been proposed by Demekov and Trakhtengerts (1994), who demonstrated the periodic generation of such particles by the periodic amplification of whistler-mode VLF waves, taking into consideration the temporal and spatial characteristics of pulsating auroras. According to Demekov model, periodic wave-particle interaction can occur near the geomagnetic equator, with energetic particles and ELF/VLF waves amplified to a certain level in a field aligned duct filled with cold plasma. ELF/VLF waves propagate and reflect in the duct, which acts as a resonator. Energetic particles are supplied into the duct continuously. If an asymmetry exists in the mechanism proposed by Demekov, it may occur in the wave-particle interaction or the precipitation process.

In the case of ELF/VLF emission, it is generally accepted that wave-particle interaction occurs near the geomagnetic equator (Kennel and Petschek, 1966; Tsurutani and Smith, 1977). It has further been deduced that the source of precipitating particles which produce pulsating auroras must be close to the geomagnetic equator (Bryant et al., 1971). Taken together, the evidence suggests that periodic wave-particle interaction responsible for pulsating auroras takes place near the geomagnetic equator.

If the duct is a symmetrical configuration in both hemispheres, waves in both hemispheres should grow to a certain level and travel similarly and simultaneously, and then should be resonant with particles from opposite directions at the geomagnetic equator. This should produce a spatially and temporally symmetric precipitation of auroral particles. Synchronous and symmetrical features in the patchy type of pulsating aurora, reported by Fujii et al. (1987b) and previous workers (Belon et al., 1969; Davis et al., 1971; Stenbaek-Nielsen et al., 1972 ), can be explained 


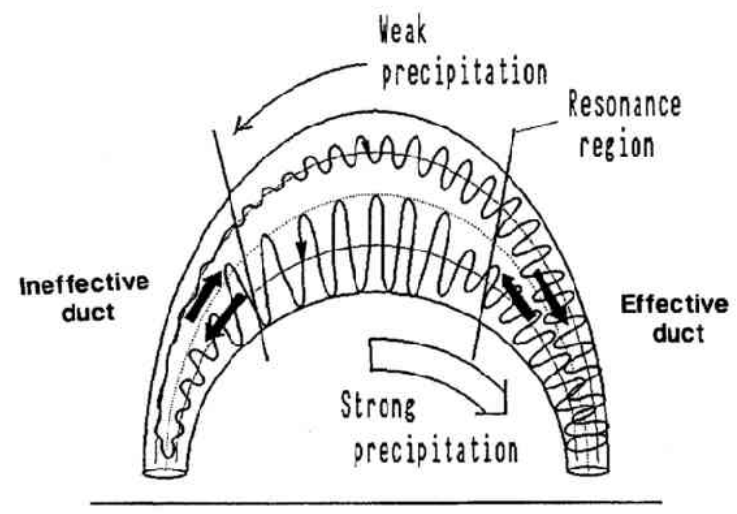

Fig. 11. A model for producing asymmetric pulsating auroras in geomagnetically conjugate areas.

by the above mechanism.

Applying these ideas to our observations, the asynchronous and asymmetrical features may be explained by an asymmetrical configuration of a duct filled with cold plasma. For waves to be propagated and reflected in the duct we require (a) a positive density gradient in the cold plasma from side to center of the duct and (b) that the wavelength be greater than the diameter at the end of the duct. If these requirements are not met in the duct, the waves are dispersed. Consider a duct having an effective configuration in one hemisphere and an ineffective one in the other hemisphere, as shown in Fig. 11. When the wave is in the ineffective part of the duct, it may be weakened almost to zero. However, on crossing the resonance region, it can grow to a certain level by a weak, periodic or non-periodic wave-particle interaction. On the other hand, the effective part of the duct, having received a grown wave from the ineffective part, can maintain strong and periodic wave-particle interaction. This mechanism can cause faint periodic or non-periodic pulsating auroras in the "ineffective" hemisphere and strong, periodic pulsating auroras in the "effective" hemisphere.

\section{Conclusion}

The conjugacy of a periodic pulsating aurora has been studied by comparing pulsating spatial patterns, intensity variations, periods, and periodicity. The analysis revealed no clear similarities in the aurora within a wide field of views of 3 stations: Husafell, Syowa and Asuka. Two possible explanations suggest themselves: (1) asymmetry in the structure of the geomagnetic field lines in opposite hemispheres, and (2) asymmetry in the generation or precipitation mechanism of the particles producing pulsating auroras. The latter hypothesis appears more likely, as the former is hardly capable of explaining our results. Repeated studies of this type should throw further light on this question.

This work was carried out using equipments at the Information Science Center and Aurora Data Center of the National Institute of Polar Research (NIPR). Valuable data from different stations were provided by members of the NIPR campaign in Iceland and the 32nd Japan Antarctic Research Expedition in 1991. We gratefully thank Dr. Ono, Dr. Fujii and Dr. Makita for our observations, data analysis and discussion.

The project in Iceland is supported by Grants-in-Aid for Overseas Science Survey (01044143, 04044165) from the Ministry of Education, Science and Culture of Japan. 


\section{REFERENCES}

Akasofu, S.-I., A study of auroral displays photographed from the DMSP-2 satellite and from the Alaska meridian chain of stations, Space Sci. Rev., 16, 617-725, 1974.

Belon, A. E., J. E. Maggs, T. N. Davis, K. B. Mather, N. W. Glass and G. F. Hughes, Conjugacy of visual auroras during magnetically quiet periods, J. Geophys. Res., 74, 1-28, 1969.

Bryant, D. A., G. M. Courtier and G. Bennett, Equatorial modulation of electrons in a pulsating aurora, J. Atmosph. Terr. Phys., 33, 859-867, 1971.

Coroniti, F. V. and C. F. Kennel, Electron precipitation pulsations, J. Geophys. Res., 75, $1279-1289,1970$.

Davidson, G. T., Self-modulated VLF wave-electron interactions in the magnetosphere: A cause of auroral pulsations, J. Geophys. Res., 84, 6517-6523, 1979.

Davidson, G. T., Pitch angle diffusion in morningside aurorae,2, The formation of repetitive auroral pulsations, $J$. Geophys. Res., 91, 4429-4436, 1986.

Davidson, G. T. and Y. T. Chiu, A closed nonlinear model of wave-particle interactions in the outer trapping and morningside auroral regions, J. Geophys. Res., 91, 13705-13710, 1986.

Davidson, G. T. and Y. T. Chiu, An unusual nonlinear system in the magnetosphere: A possible driver for auroral pulsations, J. Geophys. Res., 96, 19353-19362, 1991.

Davis, T. N., T. J. Hallinan and H. C. Stenbaek-Nielsen, Auroral conjugacy and time-dependent geometry of auroras, in The Radiating Atmosphere, edited by B. M. Mc Cormac, D. Reidel, Dordrecht-Holland, 160-169, 1971.

Demekov, A. G., On the role of the loss cone in the formation of the spike-like regime of the whistler cyclotron instability, Geomagn. Aenon., 31(6), 1099 1101, 1991.

Demekov, A. G. and V. YU. Trakhtengerts, A mechanism of formation of pulsating aurorae, J. Geophys. Res., 99 , 5831-5841, 1994.

Donovan, E. F., Modeling the Magnetic Effects of Field-Aligned Currents, J. Geophys. Res., 98, 13529-13543, 1993.

Fujii, R., N. Sato, T. Ono, H. Fukunishi, T. Hirasawa, S. Kokubun, T. Araki and Th. Saemundsson, Conjugacies of rapid motions and small-scale deformations of discrete auroras by all-sky TV observations, Mem. Natl Inst. Polar Res., Spec. Issue, 48, 72-80, 1987a.

Fujii, R., N. Sato, T. Ono, H. Fukunishi, T. Hirasawa, S. Kokubun, T. Araki and Th. Saemundsson, Conjugacies of pulsating auroras by all-sky TV observations, Geophys. Res. Lett., 14, 115-118, $1987 \mathrm{~b}$.

Iijima, T. and T. A. Potemra, Field-aligned currents in the dayside cusp observed by Triad, J. Geophys. Res., 81, 5971-5979, 1976.

Iijima, T. and T. A. Potemra, Large-scale characteristics of field-aligned currents associated with substorms, $J$. Geophys. Res., 83, 599-615, 1978.

Johnstone, A. D., The mechanism of pulsating aurora, Annales Geophysicae, 1, 397-410, 1983.

Johnstone, A. D., Pulsating aurora, Nature, 274, 119-126, 1978.

Kennel, C. F. and H. E. Petschek, Limit on stably trapped particle fluxes, J. Geophys. Res., 71, 1-28, 1966.

Makita, K., Hirasawa, T. and Fujii, R., Visual auroras observed at the Syowa station-Iceland conjugate pair, Mem. Natl Inst. Polar Res., Spec. Issue, 18, 212-225, 1981.

Minatoya, H., T. Ono, N. Sato, K. Makita, T. Yoshino, Kyouyakuten ôrora gazou syori sisutemu no kaihatsu (Development of image data processing system for the conjugate auroral TV data), Nankyoku Shiryou (Antarctic Record), 38, 115-152, 1994.

Nishitani, N., Magnetic field line connection between the ionosphere and the magnetosphere-Auroral activity and relevant magnetic field variations at geosynchronous orbit, Dr's thesis for Nagoya Univ., 1992.

Oguti, T., Observations of rapid auroral fluctuations, J. Geomag. Geoelectr., 30, 299-314, 1978.

Oguti, T., K. Hayashi, T. Yamamoto, I. Ishida, T. Higuchi and N. Nishitani, Absence of hydromagnetic waves in the magnetospheric equatorial region conjugate with pulsating auroras, J. Geophys. Res., 91, 13711-13715, 1986.

Ono, T., M. Ejiri and T. Hirasawa, Monochromatic auroral images observed at Syowa station, in Antarctica, J. Geomag. Geoelectr., 39, 65-95, 1987.

Ono, T., Data catalogue in world data center C2 for aurora (division of data collection and processing National Institute of Polar Research), 4, 173-174, 1993.

Royrvik, O. and T. N. Davis, Pulsating aurora: Local and global morphology, J. Geophys. Res., 82, 4720-4740, 1977.

Stenbaek-Nielsen, H. C., T. N. Davis and N. W. Glass, Relative motion of auroral conjugate points during substorms, J. Geophys. Res., 77, 1844-1858, 1972.

Stenbaek-Nielsen, H. C., E. M. Wescott and R. W. Peterson, Pulsating auroras over conjugate areas, Antarctic J., 8, 246, 1973.

Trakhtengerts, V. YU., V. R. Tagirov and S. A. Chernous, Flow cyclotron master and impulsive VLF emissions, Geomagn. Aeron., 26(1), 99-106, 1986.

Tsyganenko, N. A., Global quantitative models of the geomagnetic field in the cislunar magnetosphere for different disturbance levels, Planet. Space Sci., 35, 1347-1358, 1987. 
Tsurutani, B. T. and E. J. Smith, Two types of magnetospheric ELF chorus and their substorm dependences, J. Geophys. Res., 82, 5112-5128, 1977.

Yamamoto, T. and T. Oguti, Recurrent fast motions of pulsating auroral patches 1. A case study on optical and quantitative characteristics during a slightly active period, J. Geophys. Res., 87, 7603-7614, 1982.

Yamamoto, T., On the temporal fluctuations of pulsating auroral luminosity, J. Geophys. Res., 93, 897-911, 1988. 